\title{
Contextual Modulation of Memory Consolidation
}

\author{
Bertram Gerber ${ }^{1}$ and Randolf Menzel \\ Institut für Neurobiologie, Freie Universität Berlin, D 14195 Berlin, Germany
}

\begin{abstract}
We investigate olfactory memory consolidation in honeybees. Three experiments are reported that include 1024 animals in 28 experimental groups. After one pairing of odorant and sucrose reward, retention is typically nonmonotonic with a minimum 3 min after conditioning. This corresponds to the "Kamin effect" in vertebrates; the postminimum rise in retention is usually interpreted as reflecting memory consolidation. First, we test for the generality of this effect across four different odorants. The postminimum rise in retention was reproducibly observed for 1-hexanol but not for 1-octanol, limonene, or geraniol. Second, we investigate whether previous learning about the training context modulates subsequent memory consolidation. On the day before training, a reward was applied either upon placement into the future training context for $1 \mathrm{~min}$, halfway during exposure or just before removal from the context. In the latter group, the 3-min minimum in retention was eliminated; thus, in that group, forward pairings of context and reward (i.e., context exposure begins before reward is applied) lead to an associative context memory that can modulate subsequent olfactory memory consolidation. Third, we found no evidence for a modulation of olfactory memory consolidation by pre-exposure to the odorant.
\end{abstract}

The notion that it takes time to form a stable memory is common to popular and scientific reasoning and seems to capture a basic property of memory. That is, during some period after training, memories are susceptible to interference by shock, cooling, or pharmacological manipulations (Dudai 1996). This consolidation period might ensure that only the really important memories are stabilized (Carew 1996; Menzel 1999): It seems important to keep memory modifiable for some time, to erase it in case of contradictory experience, enhance it in case of affirmative experience, or to modify it according to other, already existing memories. Here, we investigate these latter effects of previous experience on memory consolidation.

To analyze memory consolidation on a behavioral level, one can make use of the temporal characteristics of retention. Kamin $(1957,1963)$ found that retention of an avoidance response in rats follows a nonmonotonic time course: Retention is high immediately after training but then decreases to a minimum after $1 \mathrm{hr}$. Then, retention increases again to reach a stable level after several days. This "Kamin effect" (Denny 1958) was subsequently found in many organisms, including humans (see Discussion). A number of authors, beginning with Kamin, have suggested that its simplest explanation is to assume the existence of two independent and additive memory systems (but see Klein and Spear 1969, 1970): one memory system that dominates retention immediately after training but then constantly loses impact and a second one that needs time to consolidate and

${ }^{1}$ Corresponding author. Present address: Institute of Physiology, University of Fribourg, CH- 1700 Fribourg, Switzerland. that is then increasingly responsible for retention. It is the "secondary" rise in retention that is taken as a behavioral indication for memory consolidation. The functional background of such a system might be that animals cannot afford to "not behave" until the stable, second memory is formed. Thus, they transiently use an independent, potentially less specific, memory system.

Here, we investigate memory consolidation as expressed by the Kamin effect in an appetitive classical conditioning paradigm during which honeybees learn to associate an odorant with a sucrose reward. Menzel (1990) has shown a retention minimum 3 min after pairing an odorant with reward. In control groups stimulated with reward alone, however, retention levels to odorant decrease monotonically, until, after $3 \mathrm{~min}$, they are back to spontaneous levels. Thus, retention immediately after a training trial was suggested to be based largely on reward-induced sensitization lasting no longer than 2-3 min. Later, retention was suggested to be increasingly based on associations of odorant and reward that reach their final strength only after $\sim 7$ min. Interestingly, retention gets more specific during the first 15 min after training (Menzel et al. 2000). During this period, memory is maximally susceptible to various interference treatments at a time point $\sim 3$ min [reversal (Menzel 1979; Menzel et al. 1993); trial repetition (Gerber et al. 1998); for local cooling studies (Menzel et al. 1974; Erber et al. 1981); extinction (Grünewald 1995; but see Menzel et al. 1993 who found a monotonically decreasing susceptibility to extinction)]. These findings indicate that processes organizing memory and necessary to support stable retention take place around $3 \mathrm{~min}$ after conditioning (for review, see Hammer and Menzel 1995; Menzel 1999).

LEARNING \& MEMORY 7:151-158 @ 2000 by Cold Spring Harbor Laboratory Press ISSN1072-0502/00 \$5.00

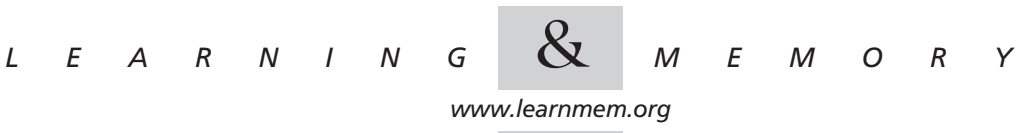


We first test for the generality of the Kamin effect across four odorants (experiment 1). This experiment avoids a potentially confounding variable that was present in previous reports. In experiment 2 we tackle the question of whether contextual memories established before training can modulate the time course of memory consolidation. In experiment 3 we follow a study by Rudy and Morledge (1994) and investigate whether unrewarded pre-exposure to the to-be-trained odorant can eliminate the Kamin effect. Rudy and Morledge (1994) found for contextual fear conditioning in rats that the Kamin effect was eliminated by prior nonreinforced exposure to the to-be-trained context. That is, their experimental approach was to make consolidation superfluous by pretraining experience. Rudy and Morledge (1994) suggested that the representation of the to-be-trained stimulus, rather than the associative link between stimulus and reinforcement, is time consuming during consolidation. In this sense, experiment 3 tests whether the Kamin effect in our preparation is due to the requirement for establishing a sensory, olfactory representation. This would question previous interpretations that stressed that the Kamin effect reflects the time it takes to form an odorant-reward association (e.g., Menzel and Sugawa 1986; Hammer and Menzel 1995; Menzel 1999).

\section{RESULTS}

\section{Experiment 1}

This experiment investigates the retention function across four different odorants (for an outline of the experimental design, see Fig. 1A).

For three out of four odorants, test response levels differ between retention interval groups (Fig. 1C; 1-hexa nol, $\chi^{2}=19.68 ; 1$-octanol, $\chi^{2}=15.61$; limonene, $\chi^{2}=22.44$; $d f=3, P<0.05$ in all cases). For geraniol, however, test response levels are uniformly high for the various retention interval groups (Fig. $1 \mathrm{C} ; \chi^{2}=5.25, d f=3, P>0.05$ ). In twogroup comparisons, for 1-hexanol, retention levels remain stable from $30 \mathrm{sec}$ to $1 \mathrm{~min}\left(\chi^{2}=0.01, d f=1, P>0.05\right)$ but decrease from $1 \mathrm{~min}$ to $3 \mathrm{~min}\left(\chi^{2}=16.48, d f=1, P<0.05\right)$. Then, retention levels rise again from $3 \mathrm{~min}$ to $10 \mathrm{~min}$ $\left(\chi^{2}=5.96, d f=1, P<0.05\right)(P=0.014)$; this effect was replicated twice (Figs. 2C and 3D). For 1-octanol, results are similar for comparisons from $30 \mathrm{sec}$ to $1 \mathrm{~min}\left(\chi^{2}=0.15\right.$, $d f=1, P>0.05)$ and from $1 \mathrm{~min}$ to $3 \mathrm{~min}\left(\chi^{2}=10.31\right.$, $d f=1, P<0.05)$; however, a comparison between retention at $3 \mathrm{~min}$ and $10 \mathrm{~min}$ just falls short of significance $\left(\chi^{2}=3.16, d f=1, P>0.05\right)$. For limonene, response levels at $30 \mathrm{sec}$ are higher than at $1 \mathrm{~min}\left(\chi^{2}=11.49, d f=1\right.$, $P<0.05)$ and then remain stable at that low level from 1 $\min$ to $3 \min \left(\chi^{2}=1.85, d f=1, P>0.05\right)$; a trend showing increasing response levels from $3 \mathrm{~min}$ to $10 \mathrm{~min}$ does not reach significance $\left(\chi^{2}=2.05, d f=1, P>0.05\right)$.

Spontaneous response levels during training are low and do not differ for either odorant in the prospective retention interval groups (Fig. 1B; 1-hexanol, $\chi^{2}=3.59$; 1-octanol, $\chi^{2}=1.87$; limonene, $\chi^{2}=3.23$; geraniol, $\chi^{2}<0.01$; $d f=3, P>0.05$ in all cases). Thus, differences in test response levels between the retention interval groups are unlikely to be due to spurious differences in group composition already manifest during training.

\section{Experiment 2}

This experiment investigates whether stimulation with reward within the future training context leads to learning about that context. In particular, it tests for the role of the temporal relation between reward and context for a modulation of subsequent olfactory memory consolidation (for an outline of the experimental design, see Fig. 2A).

The later the reward is applied during the pretraining trial, the more the Kamin effect tends to be eliminated. For early reward stimulations (in the " + " groups), the Kamin effect can be demonstrated (Fig. 2C; $\chi^{2}=10.85, d f=2$, $P<0.05)$; specifically, retention levels decrease from $30 \mathrm{sec}$ to $3 \min \left(\chi^{2}=9.64, d f=1, P<0.05\right)$ and rise again from 3 $\min$ to $15 \min \left(\chi^{2}=5.98, d f=1, P<0.05\right)(P=0.014)$. For intermediate times of reward stimulation (in the " ++ groups), the overall difference in response levels at the three retention intervals $\left(\chi^{2}=7.09, d f=2, P<0.05\right)$ is due to a decrease in response levels from $30 \mathrm{sec}$ to $3 \mathrm{~min}$ $\left(\chi^{2}=7.11, d f=1, P<0.05\right)$, whereas a trend showing increasing response levels between $3 \mathrm{~min}$ and $15 \mathrm{~min}$ does not reach significance $\left(\chi^{2}=1.00, d f=1, P>0.05\right)$. If reward is applied late during pretraining trials (in the " + " groups), retention levels are uniformly high $\left(\chi^{2}=2.39\right.$, $d f=2, P>0.05)$.

For all sets of pretraining groups, spontaneous response levels during training are uniformly low between the prospective retention interval groups (early, $\chi^{2}=3.33$; intermediate, $\chi^{2}=1.50$; late, $\chi^{2}=1.61 ; d f=2, P>0.05$ in all cases). Thus, differences in test response levels between retention interval groups are most probably not due to spurious differences in group composition already manifest during training.

\section{Experiment 3}

This experiment investigates whether pretraining experience with an odorant alone can modulate retention dynamics (for an outline of the experimental design, see Fig. 3A).

The Kamin effect remains intact after exposure to the odorant alone (Fig. 3D; $\chi^{2}=20.77, d f=2, P<0.05$ ). In pairwise comparisons, groups show decreasing response levels from $30 \mathrm{sec}$ to $3 \mathrm{~min}\left(\chi^{2}=20.69\right.$; $\left.d f=1, P<0.05\right)$; response levels increase again from $3 \mathrm{~min}$ to $15 \mathrm{~min}$ $\left(\chi^{2}=4.32 ; d f=1, P<0.05\right)(P=0.037)$.

Spontaneous response levels during pre-exposure are low and show no significant differences between the pro-

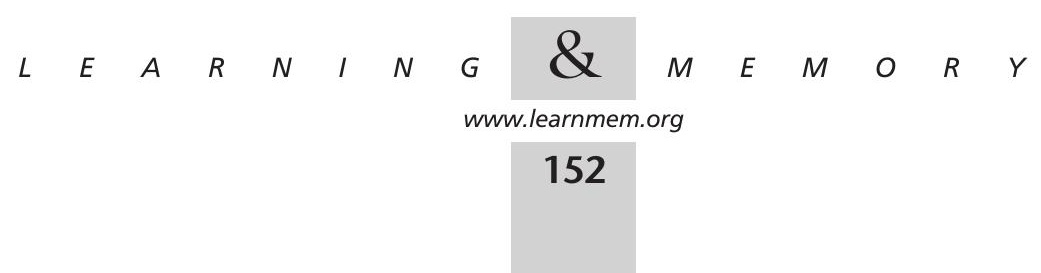


spective retention interval groups (Fig. $3 \mathrm{~B} ; \chi^{2}=4.13$; $d f=2, P>0.05$ ), a notion also true for comparisons of training performance (Fig. 3C; $\chi^{2}=0.72 ; d f=2, P>0.05$ ). Thus, differences in test response levels between the retention interval groups are unlikely to be due to spurious differences in group composition already manifest during preexposure or training.

\section{DISCUSSION}

\section{Reliability and Generality of the Kamin Effect}

The Kamin effect was observed three times using 1-hexanol (Figs. 1C, 2C, and 3D); this confirms previous work using orange scent (Mercer and Menzel 1982), carnation scent (Menzel 1990), 2-hexanol (Smith 1991), and propionic acid (Gerber et al. 1998). For 1-octanol and limonene (Fig. 1B), a similar trend was not significant. Negative results were obtained for linalool (Sandoz et al. 1995), citral, hexanal (Smith 1991), and geraniol (Fig. 1B; Smith 1991); for all those odorants, test response levels remained high throughout the testing period, and hence, it seems that they are learned particularly quickly. In the vertebrate literature, the occurrence of a nonmonotonic retention function depends on learning being incomplete (e.g., Kamin 1963). As honeybees transfer olfactory memories established at natural nectar sources to the laboratory situation (Gerber et al. 1996), the absence of the Kamin effect might be due to experience gained during foraging. In these cases, using suboptimal odorant and/or sucrose concentrations and/or using longer ISIs during training might reveal the Kamin effect, which is otherwise masked by this "too rapid" learning.

In most papers cited in the previous paragraph, the authors did not specify whether animals were removed from the experimental site between training and testing. It seems likely that, resembling the procedure reported by Gerber et al. (1998), the short retention interval groups remained, whereas the longer retention interval groups were removed from the experimental site. Such a procedure confounds effects of retention interval with a contextual change that can affect retention (Gerber et al. 1998). In the present study, all groups remained in the training situation between training and testing; we thus provide the first unconfounded evidence for a nonmonotonic retention function in honeybee classical conditioning. Apart from classical conditioning, this was also found in free-flying honeybees in dual- (Menzel 1968; Erber 1975) and multiplechoice situations (Greggers and Mauelshagen 1994).

Demonstrations of the Kamin effect in other systems have revealed that the timing of the minimum differs, most likely reflecting the ecological particulars of a species (Menzel 1999). Both in auditory shuttle box avoidance learning (Kamin 1957, 1963; Denny and Ditchman 1962) and in single-trial contextual fear conditioning (Rudy and Morledge 1994), rats show a minimum in retention $1 \mathrm{hr}$ after training. In a visual one-way avoidance task, the minimum was located between $1 \mathrm{hr}$ and $4 \mathrm{hr}$ after training (Klein and Spear 1969). In single-trial response suppression, retention is lowest $2 \mathrm{hr}$ after training (Pinel and Cooper 1966). In single-trial step-through avoidance, mice were shown to perform their worst $30 \mathrm{~min}$ after training (Zerbolio 1969; Robustelli et al. 1970). Using mice in an appetitive bar pressing task, Belcadi-Abbassi and Destrade (1995) showed a retention minimum $85 \mathrm{~min}$ after training. In goldfish, retention after a single conditioning trial was lowest 1 min after animals were trained to avoid their natural escape behavior from a flowing water well into a calm one (Riege and Cherkin 1971), whereas in octopus, retention was worst $8 \mathrm{hr}$ after animals were trained to suppress their natural attack behavior toward food items (Sanders and Barlow 1971). In a recent study on memory-guided saccadic eye movements in humans, it was shown that saccadic targeting errors peak $20 \mathrm{sec}$ after presentation of the target cue (Ploner et al. 1998). Taken together, in conditioning procedures ranging from honeybees and octopus to goldfish, mice, and man, retention is often a nonmonotonic minimum function. As this dynamic is phylogenetically so widespread and occurs in paradigms using either appetitive or aversive reinforcement or, as in the human study, no external reinforcement at all, it seems to reflect a basic property of memory.

\section{No Modulation of the Kamin Effect by Odorant Pre-exposure}

It was demonstrated in experiment 3 (Fig. 3) that pre-exposure to the to-be-trained odorant leaves the Kamin effect intact. In contrast, Rudy and Morledge (1994) have shown that the retention minimum in contextual fear conditioning in rats is eliminated by nonreinforced pre-exposure to the to-be-trained context. Based on this finding, they argued that generating a representation of the context, rather than an associative link between context and reinforcement, is time-consuming during memory consolidation. Analogous to this case, the fact that in our experiments odorant preexposure does not eliminate the retention minimum supports the belief that it is not a representation of the odorant itself that must be constructed. Of course, this invites a parametric reanalysis, varying, for example, the pre-exposure to training interval or the timing of odorant presentation during pre-exposure. In the absence of such studies, however, the most plausible interpretation of the Kamin effect remains that the associative link between odorant and rewards needs time to consolidate (Menzel and Sugawa 1986; Hammer and Menzel 1995; Menzel 1999). This notion is based on the finding that the postminimum rise in retention is observed after odorant-reward pairings but not after presentations of the reward alone (for details, see Introduction) (Menzel 1990).

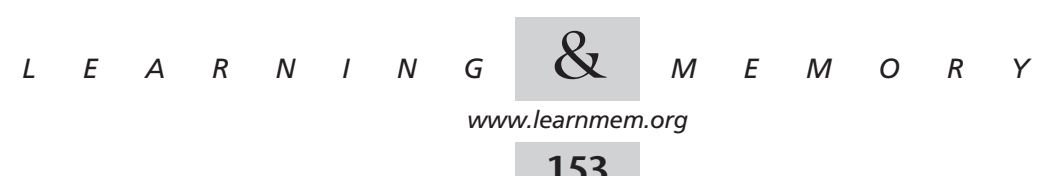




\section{Modulation of the Kamin Effect by Contextual Memories}

It was demonstrated in experiment 2 (Fig. 2) that reward application within the future training context can eliminate the Kamin effect by increasing response levels at intermediate (3-min) retention intervals. Importantly, this effect depended on the temporal relation of context and reward: If reward was applied immediately after animals were placed into the context (in the + group), the Kamin effect re- mained intact. If, however, animals had the opportunity to stay in the context for about a minute (in the + group), the retention minimum was eliminated. Because in this experiment the temporal, predictive relation of context and reward is the critical parameter, we conclude that the effect of reward stimulation involves an associative process between context and reward. This is the first report of an associative context effect for classical conditioning of the proboscis extension response in honeybees.

\section{A Outline}

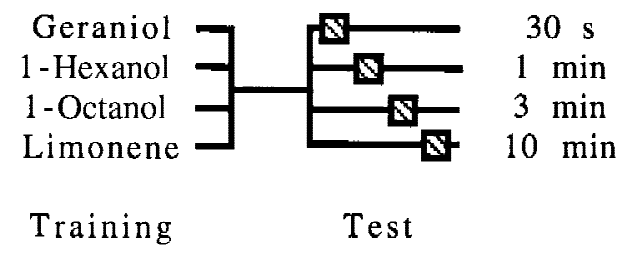

\section{B Training}
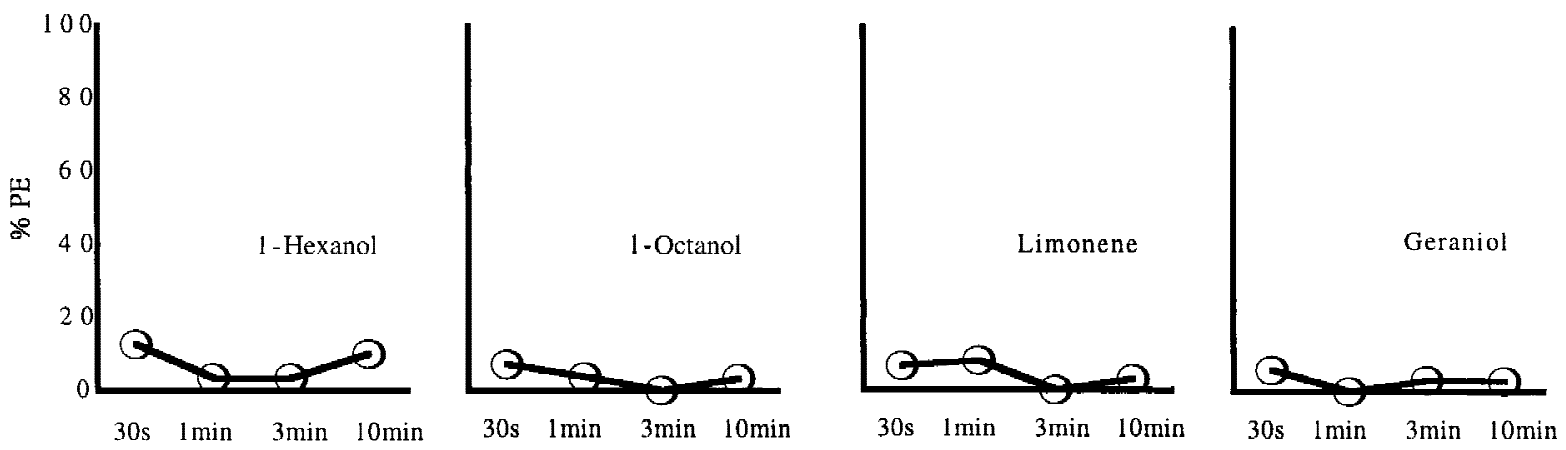

Prospective Retention Interval

\section{Test}
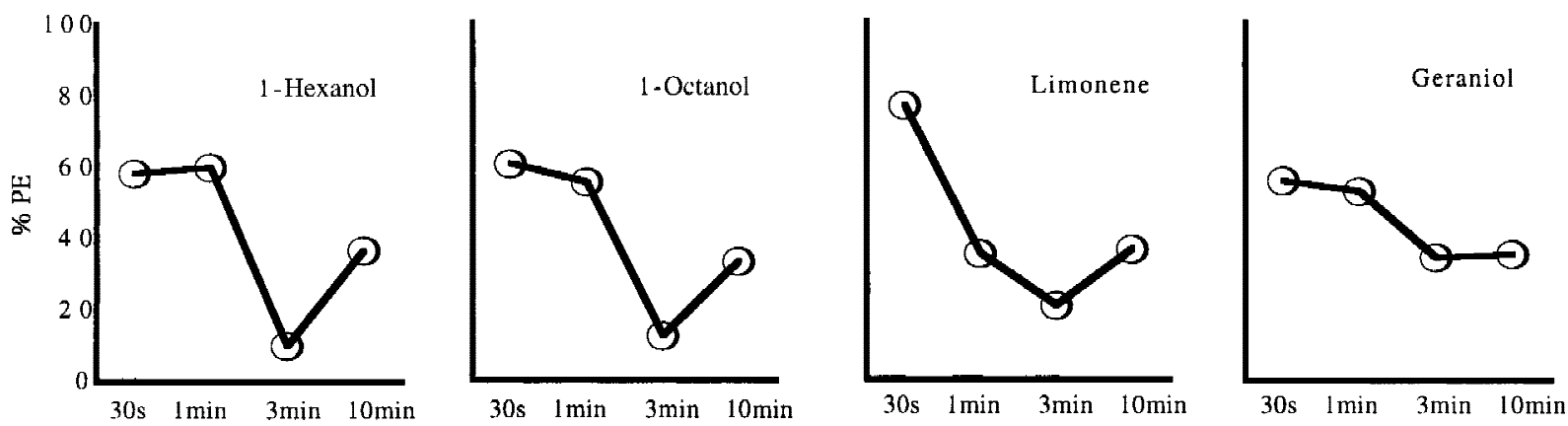

Retention Interval

Figure 1 Results of experiment 1, testing for the generality of the Kamin effect across four odorants. (A) An outline of the experimental design. $(B, C)$ The percentages of bees extending the proboscis $(\% \mathrm{PE})$ in response to odorant during training $(B)$ and test $(C)$. Sample sizes are, from left to right for 1-hexanol, 24, 30, 30, 30; for 1-octanol, 28, 27, 24, 30; for limonene, 30, 37, 34, 33; for geraniol, 34, 34 , 32, 34 . For statistical comparisons see text.

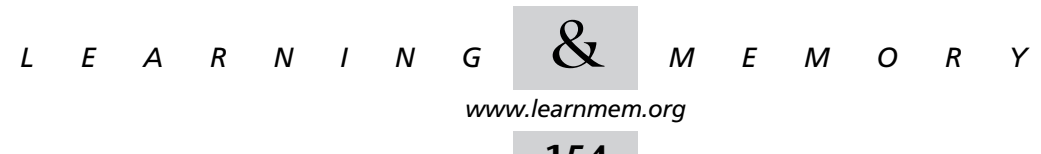


Our results suggest that forward pairings of context and reward (i.e., context exposure begins before reward is applied as in the + group) can lead to excitatory memories for the context, whereas backward pairings (i.e., context exposure outlasts reward application as in the + group) cannot. This latter finding corresponds to the "immediate shock effect" in contextual fear conditioning of rats and mice where electric shock applied immediately after animals were placed into the training chamber failed to support contextual fear conditioning (Fanselow 1990; Milanovic et al. 1998).

In the case of the + group in the present study, the relatively high 3-min response levels could thus be due to excitatory context associations facilitating olfactory memory consolidation. As the context in the present study most probably includes visual stimuli, this corresponds to the finding that visual pretraining can enhance olfactory learning (Gerber and Smith 1998; but see Couvillon et al. 1997). In particular, integration of an odorant-reward association into its context might be necessary for the developing odorantreward association to become functional. If the appropriate contextual memory already exists, the developing odorant-reward association can be integrated much faster. The minimum in retention would thus, in addition to the consolidation of the odorant-reward association, partially reflect the time it takes to form an appropriate context representation. This agrees with the findings of Gerber et al. (1998) that showed that 3 min after training, response levels are higher when animals had remained in the training context between training and testing than they were when they had been removed from it.

Alternatively, context memories themselves could be the basis for retention. For the context's visual dimensions, this seems unlikely; Gerber and Smith (1998)

\section{A Outline}

\section{B Training}

\section{Test}

have demonstrated that visual cues, although able to modulate olfactory learning, cannot release proboscis extension on their own (see also Hellstern et al. 1998). Furthermore, if context memories were able to support responses, this should already appear during training. This is, however, not the case (Fig. 2B). This latter argument also makes it un-
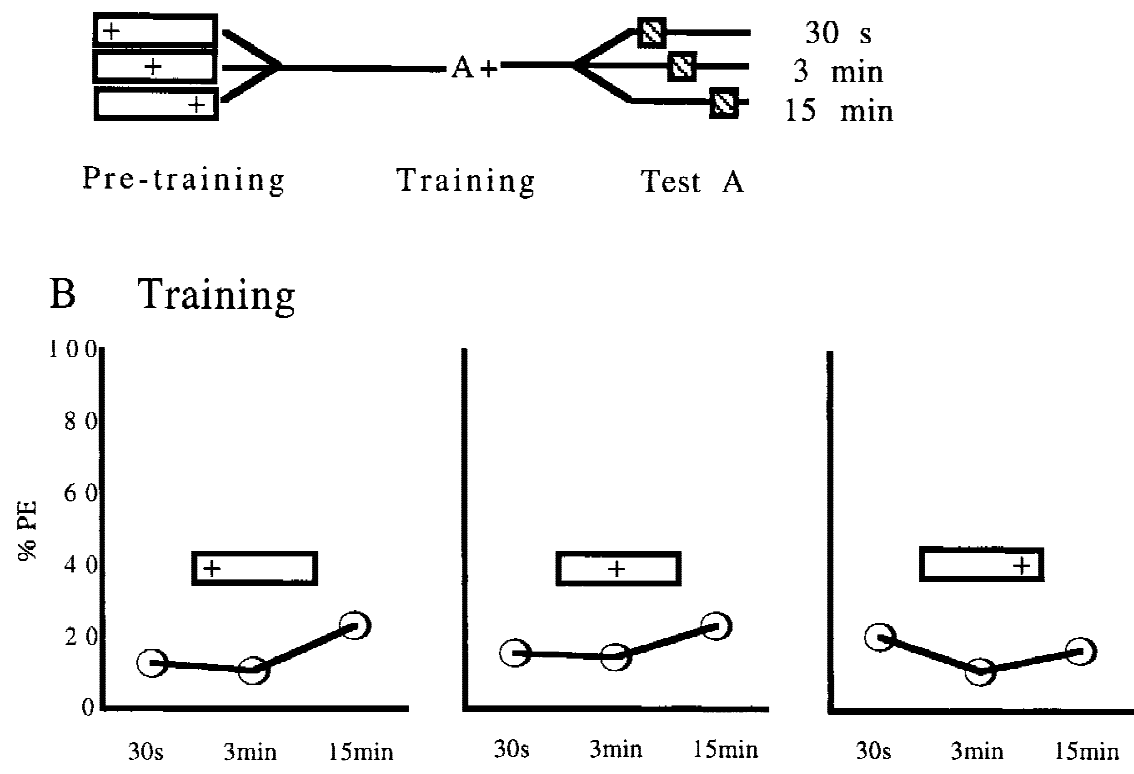

Prospective Retention Interval
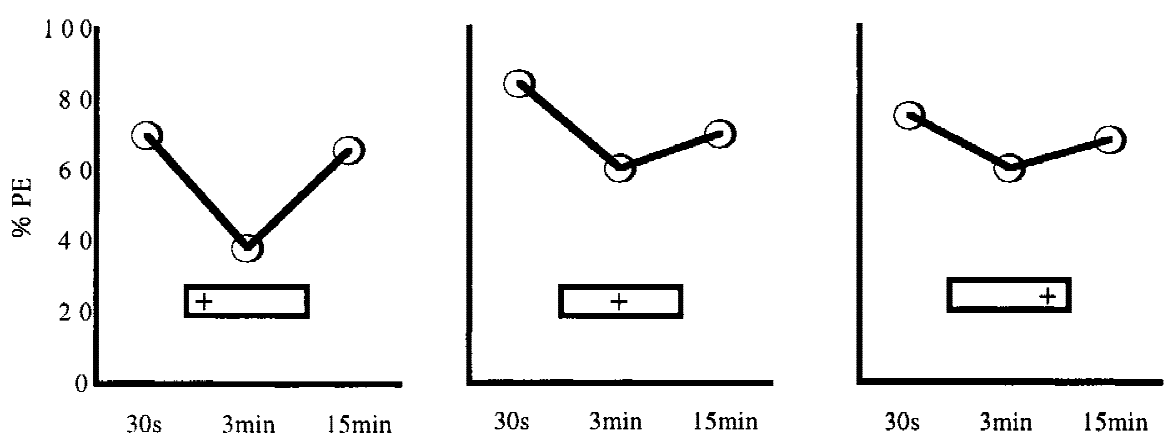

Retention Interval

Figure 2 Results of experiment 2, testing for the modulation of the Kamin effect by prior presentations of reward in the training context. $(A)$ An outline of the experimental design: $(+-$ Animals received reward immediately after being placed into the experimental context; $\left({ }_{+}\right)$ reward was delivered halfway through the 1-min context exposure; $(++)$ reward stimulation was delivered immediately before animals were removed from the context. $(B, C)$ The percentages of bees extending the proboscis (\% PE) in response to odorant during training $(B)$ and test $(C)$. Note that no pretraining values can be presented because pretraining does not involve odorant stimulation. Sample sizes are, from left to right, for the + group, 47, 47, 47; for the + group, 51, 48, 47; for the + group, 48, 45, 47. For statistical comparisons see text.

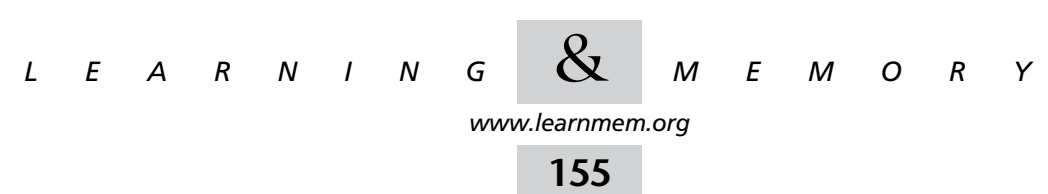




\section{A Outline}

A

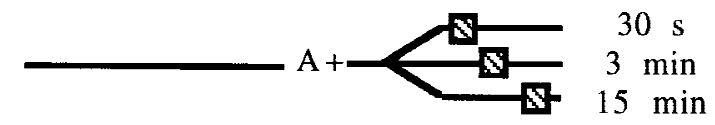

$\begin{array}{ccc}\text { Pre-exposure } & \text { Training } & \text { Test A } \\ \text { B } & \text { Pre-exposure }\end{array}$

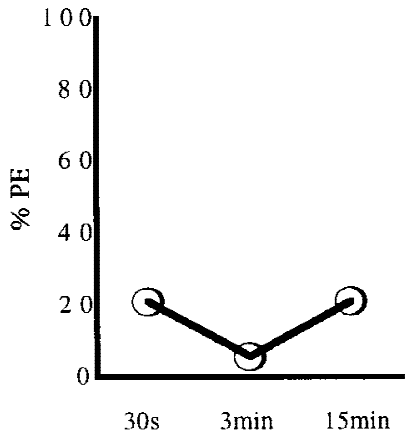

Prospective Retention Interval

\section{Training}

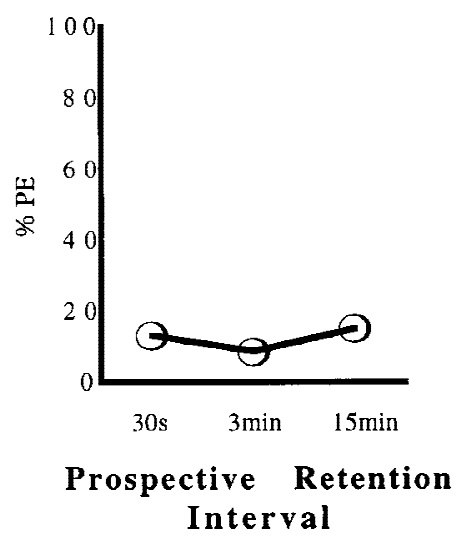

D Test

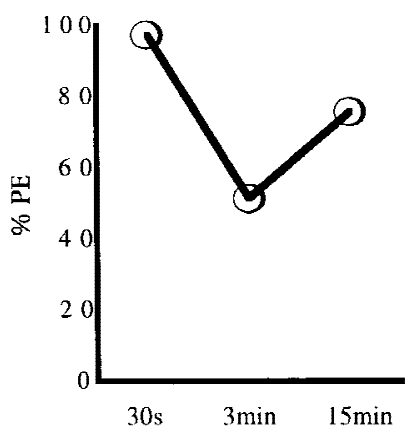

Retention Interval likely that contextual memories facilitate olfactory responding, rather than olfactory memory consolidation as suggested above.

\section{MATERIALS AND METHODS}

This study reports three experiments with 28 experimental groups and a total of 1024 animals. Honeybees (Apis mellifera carnica) were caught, cooled, and restrained in harnesses that allow movement of antennae and mouthparts, including the proboscis (Kuwabara 1957; Bitterman et al. 1983). Ten minutes after recovery, honeybees were fed to satiation with a $1.25 \mathrm{~m}$ sucrose solution. Then, animals were kept overnight at $18^{\circ} \mathrm{C}-20^{\circ} \mathrm{C}$ in a dark and humid box. Ten minutes before the experiments, the honeybees were checked for intact reflexes: extension of the proboscis beyond the virtual line between the opened mandibles after one antenna was touched with 1.25 м sucrose solution. Animals that did not show the reflex $(<5 \%)$ were not used in the experiments. After experiments were finished, all animals were again checked for their reflexes; the lack of a reflex $(<10 \%)$ was taken as a behavioral indication of death, and the respective animals were discarded.

The conditioned stimulus used was a 4 -sec pulse of odorant. On each experimental day, $4 \mu \mathrm{l}$ of odorant were applied to a fresh strip of filter paper, which was then placed into a 1-ml plastic syringe. During periods of odorant delivery, a gentle airflow provided by a standard aquarium pump was shunted through this syringe. Airflow was controlled by computer-driven solenoid valves supplied by The Lee Company, Essex, CT. Such stimulation has a mechanosensory component (air puff), but the olfactory stimulus has a substantially higher salience (Menzel 1990), so that retention is largely based on olfactory memories.

Odorant-loaded air was removed by an exhaust system mounted behind the honeybees. The unconditioned, rewarding stimulus was a $1.25 \mathrm{~m}$ sucrose solution delivered by touching both antennae with an $\sim 1 \mu \mathrm{l}$ droplet of this solution and then allowing the honeybees to feed for $2 \mathrm{sec}$, with reward delivery lasting for a total of $3 \mathrm{sec}$. During training trials, reward delivery started $1 \mathrm{sec}$ before odorant offset, leading to an onset-onset ISI of $3 \mathrm{sec}$ and to a 1-sec overlap of odorant and reward.

The experiments investigate the temporal dynamics of singletrial retention. Therefore, all animals received one rewarded training trial with an odorant (indicated by A+). In different groups of animals, retention was assessed after different time intervals, ranging from $30 \mathrm{sec}$ to $15 \mathrm{~min}$. At the beginning of the training trials, animals were removed from their resting positions and were then allowed a 20-sec accommodation period in front of the exhaust system. Then, odorant and reward were delivered as specified above. Afterwards, animals were left untreated until they received the test stimulation with the odorant. It is important to note that, in all experimental groups, the animals remained in front of the exhaust system between training and testing.

Experiment 1 investigated the temporal dynamics of singletrial retention for four different odorants: geraniol, 1-hexanol, 1-octanol, and limonene. Accordingly, four sets of groups were run

Figure 3 Results of experiment 3, testing for the modulation of the Kamin effect by prior odorant pre-exposure. $(A)$ An outline of the experimental design: $(\mathrm{A}+) \mathrm{A}$ rewarded presentation of the odorant; $(A)$ a presentation of the odorant alone. $(B-D)$ The percentages of bees extending the proboscis (\% PE) in response to odorant during pre-exposure $(B)$, training $(C)$, and test $(D)$. Sample sizes are, from left to right, 38, 35, 33. For statistical comparisons see text.

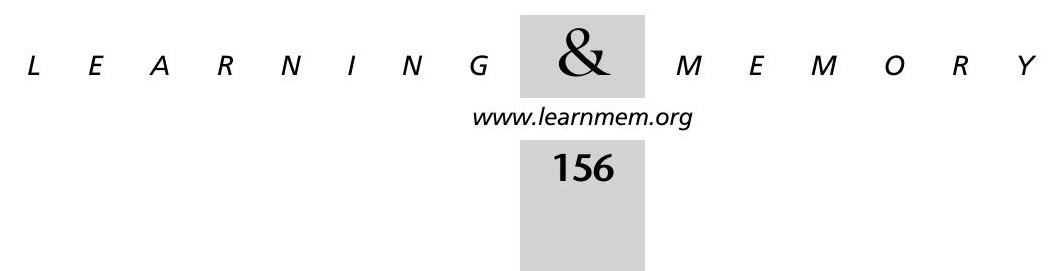


using either of these odorants. Within each set, four groups received one training trial each but were tested after either $30 \mathrm{sec}, 1$ $\mathrm{min}, 3 \mathrm{~min}$, or $10 \mathrm{~min}$ (for an outline of this procedure, see Fig. 1A). Because experiment 1 suggested that the temporal dynamics of single-trial retention might be especially pronounced for 1-hexanol (Fig. 1B), we used that odorant exclusively in experiments 2 and 3.

Experiment 2 investigated whether animals form memories for the future training context and whether such memories can affect the temporal dynamics of single-trial retention as expressed the next day in the same context. To induce learning about the future training context, three sets of groups received a single reward stimulation within that context. Different sets of groups received reward either immediately $(5 \mathrm{sec})$ after being placed into the context (indicated by + ) or immediately $(5 \mathrm{sec}$ ) before being removed from it $(+)$; the third set received reward about halfway through, that is, $24 \mathrm{sec}$ after being placed into the context $(+)$. Within each set, three groups received one training trial each the following day but were tested after either $30 \mathrm{sec}, 3 \mathrm{~min}$, or $15 \mathrm{~min}$ (for an outline of this procedure, see Fig. 2A).

Experiment 3 investigated whether unrewarded odorant preexposure affects the temporal dynamics of single-trial retention. Therefore, all three groups of animals received stimulation with A alone, a presentation of the oderant alone. The next day, all groups received one training trial each but were tested after either $30 \mathrm{sec}$, $3 \mathrm{~min}$, or $15 \mathrm{~min}$ (for an outline of this procedure, see Fig. 3A). During pre-exposure trials, odorant was applied as specified for training trials; after stimulation with odorant, animals were left untreated for $34 \mathrm{sec}$ and were then removed to their resting positions.

Animals were not fed between pretraining/ pre-exposure and training days. Under these conditions, mortality was $<10 \%$. All chemicals were obtained from SIGMA. Data are presented as the percentage of honeybees showing conditioned proboscis extension in response to odorant (\% PE). During training trials, a conditioned response was counted if the proboscis was extended between odorant onset and reward onset; during tests, any proboscis extension within $10 \mathrm{sec}$ after odorant onset was counted. The term "spontaneous response levels" used in Results refers to the response levels upon first odorant presentation. Data were analyzed for homogeneity with $\chi^{2}$ tests and were regarded as significant if $P<0.05$.

\section{ACKNOWLEDGMENTS}

This work was supported by the Studienstiftung des Deutschen Volkes (B.G.) and DFG grant Sonderforschungsbereich 515 (R.M.). We gratefully acknowledge the experimental help and good spirits of Daniel Wüstenberg and Marc Vehlow. Thanks to Andre Fiala, Uwe Greggers, Frank Hellstern, Dirk Müller, and Phillippe Tobler for continuous discussions and comments on earlier versions of this manuscript.

The publication costs of this article were defrayed in part by payment of page charges. This article must therefore be hereby marked "advertisement" in accordance with 18 USC section 1734 solely to indicate this fact.

\section{REFERENCES}

Belcadi-Abbassi, W. and C. Destrade. 1995. Post-test apamin injection suppresses a Kamin- like effect following a learning session in mice. NeuroReport 6: 1293-1296.

Bitterman, M.E., R. Menzel, A. Fietz, and S. Schäfer. 1983. Classical conditioning of proboscis extension in honeybees (Apis mellifera). $J$. Comp. Psycho. 97: 107-119.

Carew, T.J. 1996. Molecular enhancement of memory formation. Neuron. 16: 5-8.

Couvillon, P.A., L. Arakaki, and M.E. Bitterman. 1997. Intramodal blocking in honeybees. Anim. Learn. and Behav. 25: 277-282.

Denny, M.R. 1958. The "Kamin effect" in avoidance conditioning. Am. Psychologist 13: 419.

Denny, M.R. and R.E. Ditchman. 1962. The locus of maximal "Kamin effect" in rats. J. Comp. Physiol. Psychol. 55: 1069-1070.

Dudai, Y. 1996. Consolidation: Fragility on the road to the engram. Neuron 17: 367-370.

Erber, J. 1975. The dynamics of learning in the honeybee (Apis mellifera carnica). I. The time dependence of the choice reaction. J. Comp. Physiol. (A) 99: 231-242.

Erber, J., T. Masuhr, and R. Menzel. 1981. Localisation of short-term memory in the brain of the bee, Apis mellifera. Physiol. Entomol. 5: 343-358.

Fanselow, M.S. 1990. Factors governing one trial contextual fear conditioning. Anim. Learn. Behav. 18: 264-270.

Gerber, B. and B.H. Smith. 1998. Visual modulation of olfactory learning in honeybees. J. Exp. Biol. 201: 2213-2217.

Gerber, B., N. Geberzahn, F. Hellstern, J. Klein, O. Kowalsky, D. Wüstenberg, and R. Menzel. 1996. Honeybees transfer olfactory memories established during flower visits to a proboscis extension paradigm in the laboratory. Anim. Behav. 52: 1079-1085.

Gerber, B., D. Wüstenberg, A. Schütz, and R. Menzel. 1998. Temporal determinants of olfactory long-term retention in honeybees: Non-monotonous effects of the training trial interval. Neurobiol. Learn. Mem. 69: 71-78.

Greggers, U. and J. Mauelshagen. 1994. The composition of short term and long term memory components in free-flying honeybees. In Göttingen Neurobiology Report 1994 (eds. N. Elsner and H. Breer), abstract 828. Thieme, Stuttgart, Germany, and New York, NY.

Grünewald, B. 1995. "Das Lernverhalten der Honigbiene: Elektrophysiologische und morphologische Charakterisierung von Rückkopplungsneuronen des Pilzkörpers." Ph.D. thesis, Freie Universität Berlin, Berlin, Germany.

Hammer, M. and R. Menzel. 1995. Learning and memory in the honeybee. J. Neurosci. 15: 1617-1630.

Hellstern, F., R. Malaka, and M. Hammer. 1998. Backward inhibitory learning in honeybees: A behavioral analysis of reinforcement processing. Learn. \& Mem. 4: 429-444.

Kamin, L.J. 1957. The retention of an incompletely learned avoidance response. J. Comp. Physiol. Psychol. 50: 457-460.

- 1963. The retention of an incompletely learned avoidance response: Some further analyses. J. Comp. Physiol. Psychol. 56: 719-722.

Klein, S.B. and N.E. Spear. 1969. Influence of age on short-term retention of active-avoidance learning in rats. J. Comp. Physiol. Psychol. 69: 583-589.

- 1970. Reactivation of avoidance-learning memory in the rat after intermediate retention intervals. J. Comp. Physiol. Psychol. 72: 498-504.

Kuwabara, M. 1957. Bildung eines bedingten Reflexes von PAVLOVs Typus bei der Honigbiene, Apis mellifica. J. Fac. Sci. Hokkaido Univ. Ser. VI Zool. 13: 458-464.

Menzel, R. 1968. Das Gedächtnis der Honigbiene für Spektralfarben I. Kurzzeitiges und langzeitiges Behalten. Zeitschrift für vergleichende Physiologie 60: 82-102.

- 1979. Behavioural access to short-term memory in bees. Nature 281: 368-369

1990. Learning, memory and "cognition" in honeybees. In Neurobiology of comparative cognition (eds. R.P. Kesner and D.S. Olton), pp. 237-292. Laurence Erlbaum, London, UK. . 1999. Memory dynamics in the honeybee. J. Comp. Physiol. (A) 185: 323-340.

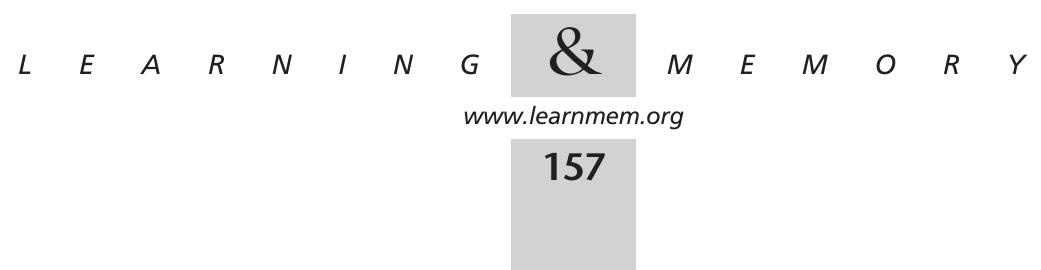


Menzel, R. and M. Sugawa. 1986. Time course of short-term memory depends on associative events. Naturwissenschaften 73: 564-565.

Menzel, R., J. Erber, and T. Masuhr. 1974. Learning and memory in the honeybee. In Experimental analysis of insect behavior (ed. L. Barton-Brown), pp. 195-217. Springer, Berlin, Germany.

Menzel, R., U. Greggers, and M. Hammer. 1993. Functional organisation of appetitive learning and memory in a generalist pollinator, the honeybee. In Insect learning-Ecological and evolutionary perspectives (eds. D.R. Papaj and A.C. Lewis), pp. 79-125. Chapman and Hall, New York, NY, and London, UK.

Menzel, R., M. Giurfa, B. Gerber, and F. Hellstern. 2000. Cognition in insects: The honeybee as a study case. In Evolution and cognition (eds. G. Roth and M. Wullimann). J. Wiley \& Sons, Chichester, UK. (In press.)

Mercer, A.R. and R. Menzel. 1982. The effect of biogenic amines on conditioned and unconditioned responses to olfactory stimuli in the honeybee, Apis mellifera. J. Comp. Physiol. (A). 145: 363-368.

Milanovic, S., J. Radulovic, O. Laban, O. Stiedl, F. Henn, and J. Spiess. 1998. Production of the Fos protein after contextual fear conditioning of C57BL/6N mice. Brain Res. 784: 37-47.

Pinel, J.P. and R.M. Cooper. 1966. Demonstration of the Kamin effect after one-trial avoidance learning. Psychon. Sci. 4: 17-18.

Ploner, C.J., B. Gaymard, S. Rivaud, Y. Agid, and C. Pierrot-Deseilligny.
1998. Temporal limits of spatial working memory in humans. Eur. $J$. Neurosci. 10: 794-797.

Riege, W.H. and A. Cherkin. 1971. One trial learning and biphasic time cource of performace in the goldfish. Science 172: 966-968.

Robustelli, F., A. Geller, and M.E. Jarvik. 1970. Biphasicity of the incubation curve. Psychon. Sci. 20: 129-130.

Rudy, J.W. and P. Morledge. 1994. Ontogeny of contextual fear conditioning in rats: Implications for consolidation, infantile amnesia, and hippocampal system function. Behav. Neurosci. 108: 227-234.

Sanders, G.D. and J.J. Barlow. 1971. Variations in retention performance during long-term memory formation. Nature 232: 203-204.

Sandoz, J.-C., B. Roger, and M.-H. Pham-Delegue. 1995. Olfactory learning and memory in the honeybee: Comparison of different classical conditioning procedures of the proboscis extension response. Comptes Rendus de l'Academie des Sciences, Paris 318: 749-755.

Smith, B.H. 1991. The olfactory memory of the honeybee (Apis mellifera): I. Odorant modulation of short- and intermediate-term memory after single trial conditioning. J. Exp. Biol. 161: 367-382.

Zerbolio, D.J. 1969. Memory storage: The first posttrial hour. Psychon. Sci. 15: $57-58$

Received October 27, 1999; accepted in revised form April 4, 2000. 


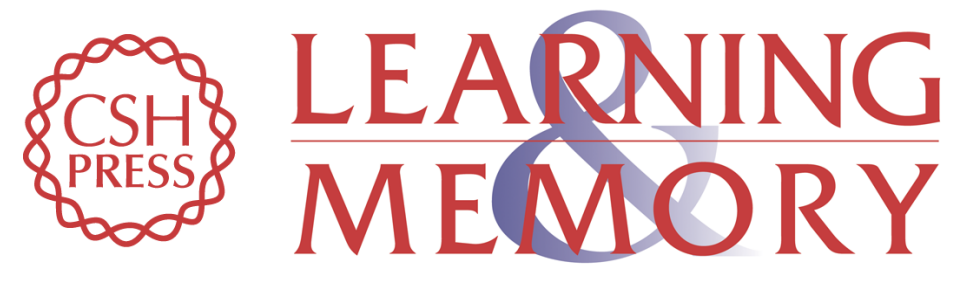

\section{Contextual Modulation of Memory Consolidation}

Bertram Gerber and Randolf Menzel

Learn. Mem. 2000, 7:

Access the most recent version at doi:10.1101//m.7.3.151

References This article cites 29 articles, 5 of which can be accessed free at: http://learnmem.cshlp.org/content/7/3/151.full.html\#ref-list-1

License

Email Alerting Receive free email alerts when new articles cite this article - sign up in the box at the Service top right corner of the article or click here. 